\title{
Reply to Letter to Editor "Obturator Hernia with Kyphosis". Kim YW, Kim IY. DOI 10.1007/s10029-013-1189-1
}

\author{
J. J. Leow $\cdot$ J. K. Low
}

Received: 3 October 2013/ Accepted: 6 November 2013/Published online: 7 December 2013

(C) Springer-Verlag France 2013

Keywords Obturator · Hernia - Conservative management $\cdot$ Non-operative $\cdot$ Patient autonomy

We thank Kim and Kim for their letter [1] describing a fascinating case of a non-surgically managed spontaneous resolution of an obturator hernia in an elderly kyphotic woman. Both our cases highlights that abdominal computed tomography (CT) scan is the gold-standard diagnostic tool $[1,2]$. It appears that nasogastric decompression and judicious progression of diet can be a possible nonoperative approach. However, we agree that the mainstay of treatment remains surgical correction [2, 3]. Recognising that surgical intervention may not always be possible in patients with poor performance status and multiple comorbid conditions, we concur with the authors that this truly is a dilemma for surgeons who encounter patients who have a correctable surgical condition, yet are unsuitable because they are not fit for general anaesthesia.

Conflict of interest The authors (JJL, JKL) each declare that they have no disclosures to make.

\section{References}

1. Kim YW, Kim IY (2013) Obturator hernia with kyphosis. Hernia. doi:10.1007/s10029-013-1189-1

2. Leow JJ, How KY, Goh MH et al (2013) Non-operative management of obturator hernia in an elderly female. Hernia. doi:10.1007/s10029-012-1036-9

3. Karasaki T, Nomura Y, Tanaka N (2013) Long-term outcomes after obturator hernia repair: retrospective analysis of 80 operations at a single institution. Hernia. doi:10.1007/s10029-013-1159-7

This comment refers to the article available at doi:10.1007/s10029-013-1189-1. 